\title{
Regulation of steroidogenesis and cholesterol synthesis by prostaglandin F-2 $\alpha$ and lipoproteins in bovine luteal cells
}

\author{
J. L. Pate and W. A. Condon* \\ Department of Dairy Science, The Ohio State University, Columbus, Ohio 43210, USA; and \\ *Department of Animal and Nutritional Sciences, University of New Hampshire, Durham, \\ NH 03824, USA
}

\begin{abstract}
Summary. Bovine luteal cells can utilize low density lipoprotein (LDL) or high density lipoprotein (HDL) as a source of cholesterol for steroidogenesis, and administration of PGF-2 $\alpha$ in vitro suppresses lipoprotein utilization. The objective of this study was to examine the mechanism by which PGF-2 $\alpha$ exerts this effect. Cultured bovine luteal cells received $0 \cdot 25 \mu \mathrm{Ci}\left[{ }^{14} \mathrm{C}\right]$ acetate $/ \mathrm{ml}$, to assess rates of de-novo sterol and steroid synthesis, with or without lipoproteins. Both LDL and HDL enhanced progesterone production $(P<0.01)$, but caused a significant reduction in the amount of radioactivity in the cholesterol fraction. PGF-2 $\alpha$ treatment inhibited the increase in lipoprotein-induced progesterone synthesis $(P<0.01)$, but did not prevent the reduction in de-novo cholesterol synthesis brought about by LDL or HDL. PGF- $2 \alpha$ alone reduced cholesterol synthesis $(P<0.01)$, but it was not as effective as either LDL or HDL. Both lipoproteins and PGF-2 $\alpha$ also decreased the amount of radioactivity in the progesterone fraction $(P<0.01)$, and the effect of PGF- $2 \alpha$ was similar to that of the lipoproteins. It is concluded that lipoproteins can enhance progesterone production and also suppress de-novo cholesterol synthesis in bovine luteal cells, but only the former effect of lipoproteins is inhibited by PGF-2 $\alpha$. Therefore, it is suggested that PGF- $2 \alpha$ allows entry of lipoprotein cholesterol into the cell, but prevents utilization for steroidogenesis. In addition, PGF-2 $\alpha$ alone can suppress cholesterol synthesis, as well as decrease conversion of cholesterol to progesterone.
\end{abstract}

Keywords: corpus luteum; PGF-2 $\alpha$; lipoproteins; cholesterol; cow

\section{Introduction}

It is now generally accepted that steroidogenic tissues can derive cholesterol from circulating lipoproteins, and this may provide the major source of substrate for steroid synthesis. Bovine luteal cells in vitro can utilize either low-density lipoprotein (LDL) or high-density lipoprotein (HDL) as a source of cholesterol for increased progesterone production (Pate \& Condon, 1982; O'Shaughnessy $\&$ Wathes, 1985). Blood-borne cholesterol appears to be physiologically important for luteal function in the cow, because elevated serum cholesterol values result in increased progesterone concentrations during the luteal phase (Talavera et al., 1985). Circulating cholesterol is probably the preferred substrate, as opposed to de-novo synthesis of cholesterol, in many species (see review by Gwynne \& Strauss, 1982; Swann \& Bruce, 1986).

Cellular cholesterol synthesis, esterification and hydrolysis are adjusted in accordance with a balance between the metabolic needs of the cell and the supply of exogenous cholesterol. In many tissues, when lipoprotein-carried cholesterol is sufficient to meet the needs of the cell, the ratelimiting enzyme in cholesterol synthesis, 3-hydroxy-3-methylglutaryl coenzyme A (HMG Co A) reductase, is suppressed (Schuler et al., 1981; Savion et al., 1982). In bovine luteal cells, cholesterol 
synthesized de novo is apparently unnecessary for progesterone synthesis when lipoproteins are present (O'Shaughnessy \& Wathes, 1985), although there is no direct evidence that lipoproteins can regulate cholesterol synthesis in these cells.

A recent study from this laboratory provided evidence that prostaglandin (PG) F-2 $\alpha$ can inhibit utilization of lipoproteins for progesterone synthesis (Pate \& Nephew, 1988). Limiting substrate supply for steroidogenesis could be one mechanism by which PGF- $2 \alpha$ exerts its luteolytic effect. However, it was not determined whether PGF-2 $\alpha$ inhibited lipoprotein binding, uptake, or utilization within the cell. Therefore, the present experiments were undertaken to determine whether lipoprotein availability could regulate de-novo cholesterol synthesis in bovine luteal cells, and to localize the inhibitory action of PGF- $2 \alpha$ in regard to lipoprotein utilization.

\section{Materials and Methods}

Cell culture. Corpora lutea were removed through the vaginal wall of non-lactating, regularly cyclic dairy cows on Days 9-12 of oestrous cycle (oestrus = Day 0 ). $\mathrm{CL}$ were placed immediately into Ham's F-12 cell culture medium (Mediatech, Washington, DC, USA) containing $24 \mathrm{~mm}-\mathrm{N}$-2-hydroxyethylpiperazine- $N$-2-ethane sulphonic acid (Hepes; Sigma Chemical Co., St Louis, MO, USA) (pH 7.35) at $4^{\circ} \mathrm{C}$, for transport to the laboratory. Luteal tissue was dissociated with collagenase (2000 U/g tissue; Type 1, Worthington, Freehold, NJ, USA) and cell suspensions were placed in serum-pretreated culture flasks $\left(25 \mathrm{~cm}^{2}\right.$; Corning Glass Works, Corning, NY, USA) as previously described (Pate \& Condon, 1982; Pate \& Nephew, 1988). All cells were cultured in serum-free Ham's F-12 culture medium (with $24 \mathrm{~mm}$-Hepes buffer) containing penicillin $(100 \mathrm{U} / \mathrm{ml})$, streptomycin $(100 \mu \mathrm{g} / \mathrm{ml})$ (Pen-Strep, K.C. Biological, Lenexa, $\mathrm{KS}$, USA), gentamicin ( $20 \mathrm{ng} / \mathrm{ml}$, Grand Island Biological, Grand Island, NY), and supplemented with insulin ( $5 \mu \mathrm{g} / \mathrm{ml})$, transferrin $(5 \mu \mathrm{g} / \mathrm{ml})$, and selenium $(5 \mathrm{ng} / \mathrm{ml})$ (ITS premix; Collaborative Research Inc., Lexington, MA, USA). Numbers of viable cells were quantified throughout the culture period as previously described (Pate \& Nephew, 1988).

Lipoprotein isolation. Lipoproteins were prepared from normal bovine serum obtained from blood collected from 5 non-lactating dairy cows. LDL (density $1.006-1.063 \mathrm{~g} / \mathrm{ml}$ ) and HDL (density $1.063-1.210 \mathrm{~g} / \mathrm{ml}$ ) were prepared by differential ultracentrifugation using $\mathrm{KBr}$ for density adjustment (Havel et al., 1955). The lipoprotein fractions were dialysed against $0.15 \mathrm{M} \cdot \mathrm{NaCl}$ and $0.3 \mathrm{~mm}$-ethylenediaminetetraacetic acid (EDTA), $\mathrm{pH} 7 \cdot 4$. The lipoprotein fractions were sterilized by passage through a $0.22 \mu \mathrm{m}$ Millipore (Bedford, MA, USA) filter, stored at $4^{\circ} \mathrm{C}$, and used within 4 weeks of preparation. Cholesterol in the lipoprotein fractions was determined by the method of Wybenga et al. (1970).

Radioimmunoassay. Progesterone secreted into the culture medium was quantified by radioimmunoassay of unextracted samples using antiprogesterone-11-bovine serum albumin (GDN-337) donated by Dr Gordon Niswender, and $\left[1,2-{ }^{3} \mathrm{H}\right]$ progesterone (New England Nuclear, Boston, MA, USA). The intra-assay coefficient of variation was $9.6 \%$, and the interassay coefficient of variation was $15.9 \%$. The limit of sensitivity was $0 \cdot 1 \mathrm{ng} / \mathrm{ml}$. All standards were assayed in quadruplicate, and all samples were assayed in duplicate. Radioactivity was quantified in a liquid scintillation counter using separate channels for ${ }^{3} \mathrm{H}$ and ${ }^{14} \mathrm{C}$.

Experimental design. In the first experiment, 36 flasks of luteal cells were established from each CL ( $n=5$, initiation of culture $=$ Day 0 ). Culture medium was replaced after $24 \mathrm{~h}($ Day $\mathrm{l})$ and at $48-\mathrm{h}$ intervals thereafter. The flasks were divided into three groups (12 flasks per group) which would receive lipoprotein treatments on Day 1, Day 5 , or Day 11 of culture. These were further subdivided into lipoprotein-free, LDL-, and HDL-treated flasks $(50 \mu \mathrm{g}$ cholesterol $/ \mathrm{ml})$, and these treatments in combination with $\mathrm{LH}(10 \mathrm{ng} / \mathrm{ml})$. The $\mathrm{LH}$ was added at the initiation of culture and replaced with each medium change. On Day 1, 5 or 11, when LDL and HDL treatments were added, all cultures also received $0.25 \mu \mathrm{Ci}\left[{ }^{14} \mathrm{C}\right]$ acetate $/ \mathrm{ml}$ (New England Nuclear), and were incubated for an additional $24 \mathrm{~h}$ at $37^{\circ} \mathrm{C}$. Because the endogenous acetate concentration was unknown, it was not possible to determine the specific activity of the precursor pool. Therefore, this method does not give a quantitative measure of cholesterol biosynthesis. However, this procedure is useful for assessing relative rates of cholesterol synthesis in response to various treatments (Schuler et al., 1979).

At the end of the $24 \mathrm{~h}$ exposure to $\left[{ }^{14} \mathrm{C}\right]$ acetate and lipoprotein, $1 \mathrm{ml}$ medium from each flask was removed and frozen for assay of progesterone. The remaining medium was extracted twice with $5 \mathrm{ml}$ anhydrous ether. The cell monolayers were rinsed with phosphate-buffered saline ( $\mathrm{pH} 7 \cdot 4)$, drained, and extracted with $5 \mathrm{ml}$ hexane:isopropanol $(3: 2, \mathrm{v} / \mathrm{v})$. The hexane:isopropanol and ether extracts were combined, dried under air at $37^{\circ} \mathrm{C}$, and stored at $-20^{\circ} \mathrm{C}$, until further analysis.

For thin-layer chromatography, samples were reconstituted in benzene:ethanol $(9: 1, v / v)$ and applied to Silica Gel $\mathrm{GF}_{254}$ t.l.c. plates (Fisher Scientific, Cincinnati, OH, USA). One-dimensional chromatography was performed in benzene:methylene chloride $(1: 1, v / v)$ followed by hexane:ethyl acetate $(5: 2, v / v)$. Progesterone and cholesterol spots, as determined by migration of standards, were eluted from the silica gel with methanol $(3 \mathrm{ml}$, twice). This method has been previously used to isolate various classes of lipids (Skipski \& Barclay, 1969) and effectively separates cholesterol and progesterone in incubation media from bovine luteal tissue (Armstrong \& Black, 1966; Condon \& Black, 1976). In a single experiment, no treatment effects were observed on other classes of lipids. The samples were dried down, 
reconstituted in $10 \mathrm{ml}$ counting cocktail (toluene with 0.132\% 2,5-diphenyloxazole (PPO); Fisher Scientific), and counted in a liquid scintillation counter. Radioactivity is expressed as disintegrations per minute (d.p.m.).

For the second experiment, cells were cultured and treated as described for Exp. 1, except that lipoproteins and $\left[{ }^{14} \mathrm{C}\right]$ acetate were added only on Day 5 . Samples were processed as described $24 \mathrm{~h}$ later. Also, on Day 0 half of the cultures received PGF-2 $\alpha$ ( $10 \mathrm{ng} / \mathrm{ml}$; Sigma Chemical Co.), which was replaced when the medium was changed on Days 1, 3 and 5. Therefore, on Day 5, treatments consisted of control, LDL, HDL, and these treatments combined with PGF-2 $\alpha$. All treatments were performed in duplicate for each CL $(n=5)$. In the second experiment, all media contained $\mathbf{L H}(10 \mathrm{ng} / \mathrm{ml})$ to promote maximal cellular synthetic capability.

Data analysis. For statistical analysis, within each experiment, all treatments within a day of culture were subjected to two-way analysis of variance. Due to heterogeneity of variance observed in amounts of progesterone production between $\mathbf{C L}$, progesterone data were logarithmically transformed before statistical analysis. When significant differences occurred, the data were further compared using the Newman-Keuls mean separation procedure to indicate significant differences between individual treatment means.

\section{Results}

\section{Experiment 1}

Bovine luteal cells were cultured in serum-free medium containing 0 or $10 \mathrm{ng} \mathrm{LH} / \mathrm{ml}$. On Day 1 , 5 , or 11 of culture, LDL or HDL were added to appropriate cultures and all cultures received $\left[{ }^{14} \mathrm{C}\right]$ acetate. Total progesterone production after a 24 -h exposure to lipoproteins is shown in Fig. 1. On Days 1 and 5, progesterone synthesis was significantly greater in cultures which were treated with LDL or HDL, as compared to lipoprotein-free cultures. Increased progesterone production in response to $\mathrm{LH}$ was only significant on Day 5 and at this time combined treatment with lipoprotein and $\mathrm{LH}$ resulted in greater steroid production than with either treatment alone. On Day 11 of culture, although the amount of progesterone detected in LH-, LDL- or HDL-treated cultures was higher than in controls, these differences were not statistically significant.

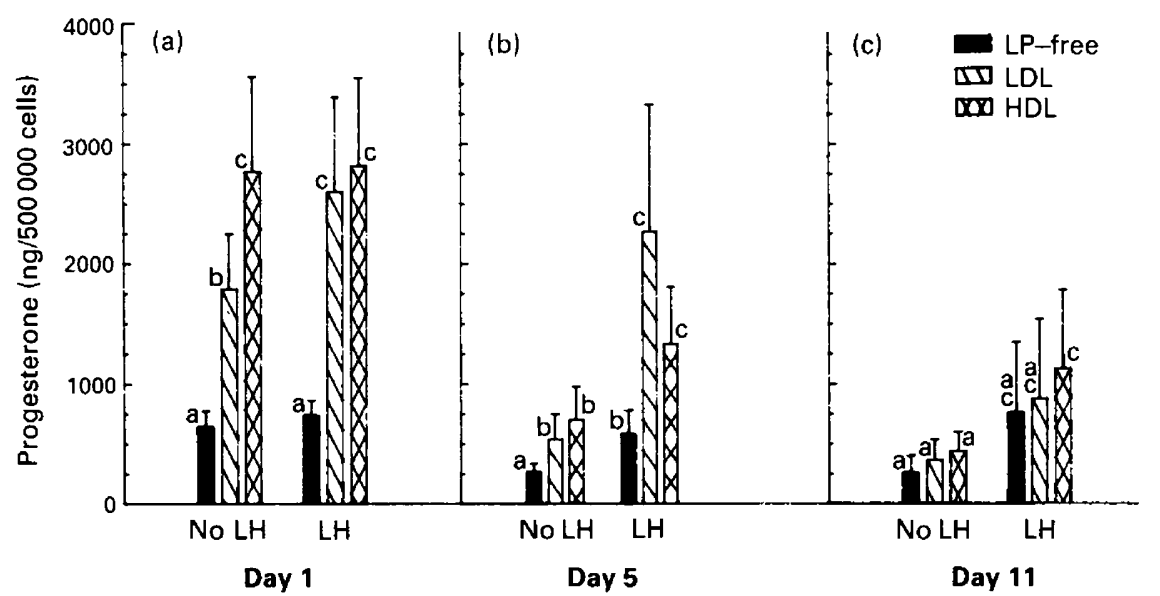

Fig. 1. Progesterone production by luteal cells in response to 24-h exposure to LDL or HDL, on Day 1 (a), 5 (b) or 11 (c) of culture. LH treatments were continuous from Day 0. Bars represent the mean \pm s.e.m.; $n=5$. Within a day of culture, bars with different superscript letters are significantly different $(P<0 \cdot 01)$.

The lipoproteins most probably increase progesterone production by providing cholesterol as a substrate for steroidogenesis. Therefore, it is likely that de-novo cholesterol synthesis would be lowered in the presence of lipoproteins. This was examined in the cultured luteal cells using ${ }^{14} \mathrm{C}$-labelled acetate incorporation into cholesterol as an indication of de-novo synthesis. It can be seen in Fig. 2 that both LDL and HDL were effective in lowering the amount of radioactivity $\left({ }^{14} \mathrm{C}\right)$ 
which was incorporated into cholesterol, thus indicating a decline in cholesterol synthesis from acetate. This effect was most dramatic on Day 5. There was no significant effect of LH on incorporation of radioactivity into cholesterol, and the lipoprotein-induced decrease in radioactivity was not altered in the presence of LH. There were no significant differences in $\left[{ }^{14} \mathrm{C}\right]$ cholesterol on Day 11. Similar treatment effects were seen in $\left[{ }^{14} \mathrm{C}\right]$ acetate incorporation into progesterone (not shown).

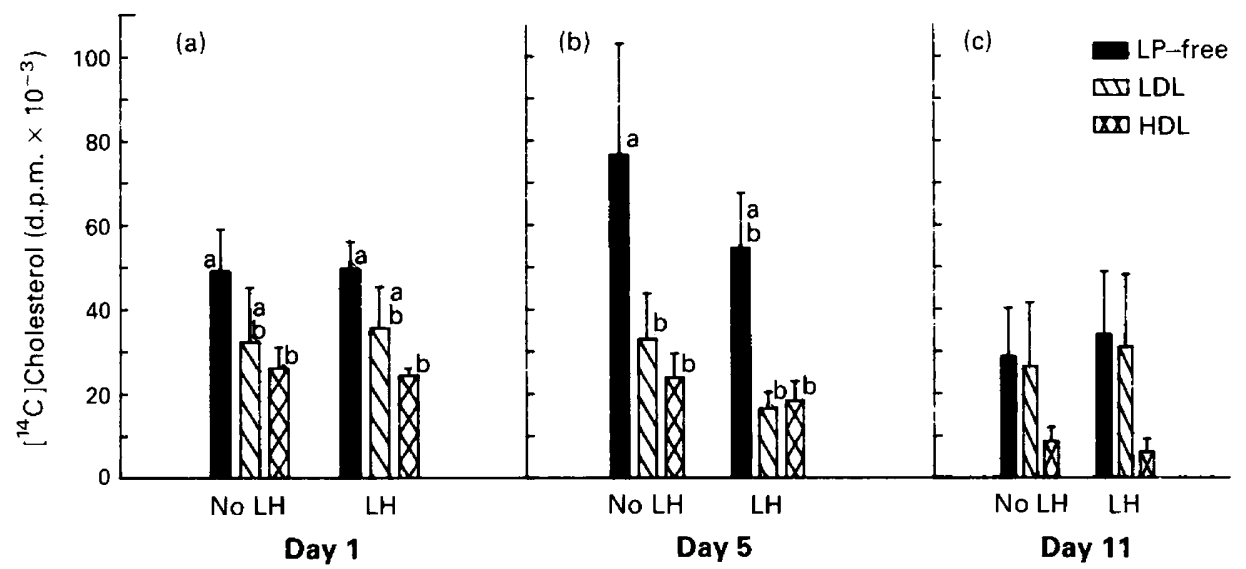

Fig. 2. Incorporation of $\left[{ }^{14} \mathrm{C}\right]$ acetate into cholesterol on Day 1 (a), Day 5 (b) or Day 11 (c). Incubation with $\left[{ }^{14} \mathrm{C}\right]$ acetate, $\mathrm{LDL}$ and $\mathrm{HDL}$ was for $24 \mathrm{~h}$. Bars represent the mean \pm s.e.m. of 5 CL. Within a day of culture, bars with different superscript letters are significantly different (a, $P<0.05 ; \mathrm{b}, P<0.01$ ).

\section{Experiment 2}

Based on the results of Exp. 1, it was decided to perform the acetate incorporation on Day 5 for the subsequent study, because this day yielded the best LH response and good lipoprotein response in terms of progesterone secretion, and the lipoproteins also effectively suppressed cholesterol synthesis. To determine what effect PGF- $2 \alpha$ would have on these responses, cells were cultured for 5 days in the presence of 0 or $10 \mathrm{ng}$ PGF- $2 \alpha / \mathrm{ml}$. All cultures also received $10 \mathrm{ng} \mathrm{LH} / \mathrm{ml}$. The effect of PGF-2 $\alpha$ on total progesterone production by these cells is depicted in Fig. 3 . As expected, PGF- $2 \alpha$ inhibited LH-stimulated progesterone (control bars), and also suppressed the elevation in steroidogenesis brought about by the presence of LDL or HDL. PGF-2 $\alpha$ therefore prevented complete utilization of the lipoproteins for steroid synthesis.

The rate of de-novo synthesis of cholesterol in these cultures is represented in Fig. 4 as the amount of $\left[{ }^{14} \mathrm{C}\right]$ acetate incorporated into the cholesterol fraction. The amount of labelled cholesterol was significantly greater in non-lipoprotein-treated cultures, as compared to treatment with LDL or HDL. Addition of PGF- $2 \alpha$ to the culture medium did not inhibit the lipoprotein-induced suppression. In fact, PGF-2 $\alpha$ alone caused a reduction in the accumulation of $\left[{ }^{14} \mathrm{C}\right]$ cholesterol, relative to control cultures. Therefore, both PGF- $2 \alpha$ and the lipoproteins (LDL and HDL) were able to decrease incorporation of $\left[{ }^{14} \mathrm{C}\right]$ acetate into cholesterol, although the lipoproteins were more effective than the prostaglandin.

Similar treatment effects were observed in regard to $\left[{ }^{14} \mathrm{C}\right]$ acetate utilization for steroidogenesis (Fig. 4). Both LDL and HDL caused a substantial reduction in the proportion of progesterone which was derived from cholesterol synthesized de novo. PGF-2 $\alpha$ also decreased the amount of radioactivity in the progesterone fraction, and this decrease was statistically similar to that produced by the lipoproteins. Also, $\left[{ }^{14} \mathrm{C}\right]$ progesterone was reduced when cells were treated with LDL or HDL, even after prolonged exposure to PGF-2 $\alpha$. The specific activity of progesterone was 


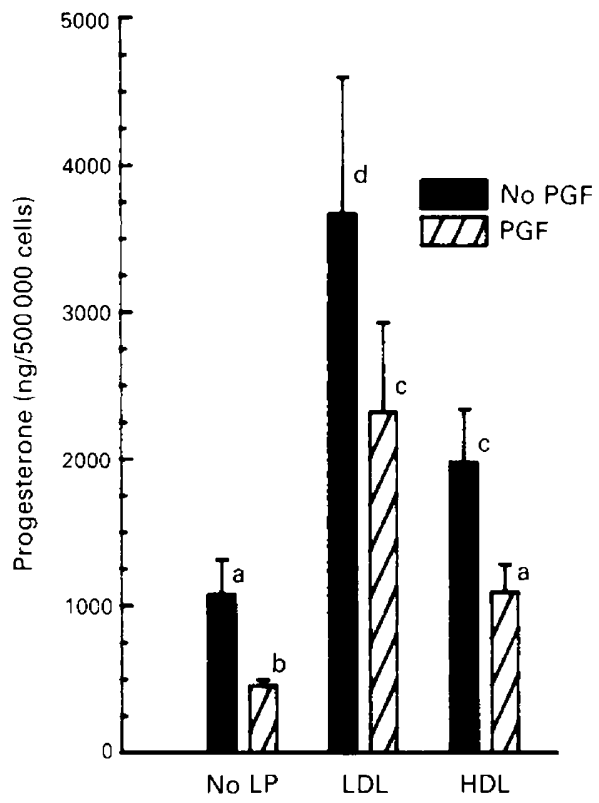

Fig. 3. Progesterone production $24 \mathrm{~h}$ after addition of LDL, HDL or no lipoprotein (No LP) on Day 5 of culture. From Day 0, all celis received $\mathrm{LH}(10 \mathrm{ng} / \mathrm{ml})$, and were cultured with (hatched bars) or without (solid bars) PGF- $2 \alpha(10 \mathrm{ng} / \mathrm{ml})$. Bars represent the mean \pm s.e.m. of $5 \mathrm{CL}$. Bars with different superscript letters are significantly different $(P<0 \cdot 01)$.
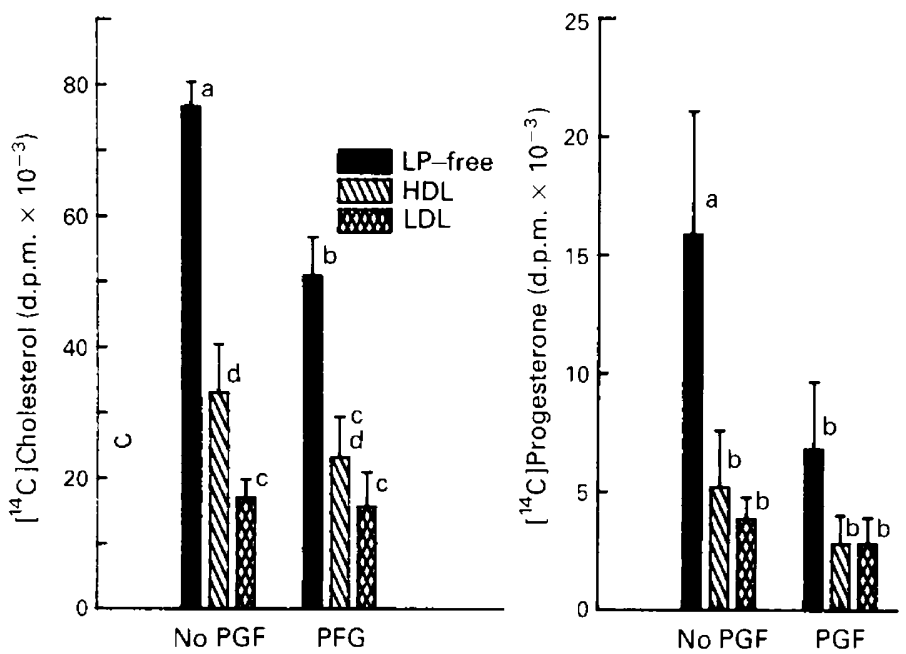

Fig. 4. Incorporation of $\left[{ }^{14} \mathrm{C}\right]$ acetate into cholesterol or progesterone after $24 \mathrm{~h}$ incubation beginning on Day 5 of culture. All cells received LH, and some received PGF-2 $\alpha$, from Day 0 . On Day 5, HDL (hatched bars), LDL (cross-hatched bars) or no lipoproteins (solid bars) were added to the culture medium. Values are mean \pm s.e.m.; $n=5$. Bars with different superscript letters are significantly different $(P<0.01)$. 
calculated for each of these samples (data not shown), and these data confirmed that the effect of the lipoproteins was not simply due to a dilution of the total pool.

\section{Discussion}

The stimulation of progesterone synthesis by the presence of LDL or HDL is consistent with earlier reports using cultured bovine luteal cells (Pate \& Condon, 1982; O'Shaughnessy \& Wathes, 1985) or cultured granulosa cells from the cow (Savion et al., 1982) or rat (Schuler et al., 1979; Schreiber et al., 1980). Furthermore, it can be seen from the results that the availability of lipoproteincholesterol can regulate de-novo sterol synthesis in bovine luteal cells, as in fibroblasts (Brown \& Goldstein, 1980), adrenal cells (Balasubramaniam et al., 1977), and granulosa cells (Schuler et al., 1979, 1981; Tureck \& Strauss, 1982).

In both experiments presented here, the assumption was made that incorporation of $\left[{ }^{14} \mathrm{C}\right]$ acetate into cholesterol represented de-novo sterol synthesis. Since the specific activity of $\left[{ }^{14} \mathrm{C}\right]$ acetate was not determined, the exact rate of cholesterol synthesis could not be calculated. However, relative changes in rates of sterol metabolism can be detected by this method (Schuler et al., 1979), which has been extensively used for this purpose (Rosenblum et al., 1981; Baranao \& Hammond, 1985; Gwynne et al., 1985). Also, it is likely that the $\left[{ }^{14} \mathrm{C}\right]$ acetate entered the cellular pool of acetyl CoA and was converted to products other than cholesterol and progesterone, such as fatty acids, but it has been previously shown that lipoproteins do not affect this process (Rosenblum et al., 1981). The finding that de-novo cholesterol synthesis is suppressed in the presence of LDL or HDL in bovine luteal cells is further supported by the large body of evidence which indicates that lipoproteins reduce the activity of HMG CoA reductase (Simpson et al., 1978; Brown \& Goldstein, 1980; Schuler et al., 1981; Savion et al., 1982). It was important, however, to confirm the existence of this regulation in bovine luteal cells, since some steroidogenic cell types rely heavily on newly synthesized cholesterol even in the presence of lipoproteins (Carr et al., 1980).

It has been previously determined in this laboratory that exposure of luteal cells in culture to prostaglandin F-2 $\alpha$ will result in a suppression of lipoprotein-enhanced progesterone production (Pate \& Nephew, 1988). The current study substantiates this finding, and an attempt was made to localize the site of action of the prostaglandin. It was reasoned that, if PGF- $2 \alpha$ prevented the entry of the lipoprotein molecule into the cell, then the cholesterol would not be available to suppress denovo sterol synthesis. Since the lipoproteins were equally effective in the absence or presence of PGF-2 $\alpha$, it appears that PGF-2 $\alpha$ allowed entry of the lipoprotein-cholesterol molecule. Further, direct measurements of intracellular cholesterol indicate that the higher concentrations in lipoprotein-treated than in control cells are not lowered by PGF-2 $\alpha$ (D. P. Grusenmeyer \& J. L. Pate, preliminary observations).

Rajkumar et al. (1985) reported that HDL binding to rat luteal membranes is not decreased after an in-vivo injection of PGF-2 $\alpha$. During PGF-2 $\alpha$-induced luteolysis, the corpora lutea of ewes and cows accumulate substantial stores of lipid (Umo, 1975; Heath et al., 1983), implying that the uptake of cholesterol is unimpaired. Therefore, it seems possible that PGF- $2 \alpha$ allows binding and internalization of lipoproteins, but utilization of the cholesterol for steroidogenesis is abrogated. This may be similar to the situation in gonadotrophin-desensitized luteal cells, in which lipoprotein uptake is increased but the cholesterol is not metabolized to progesterone (Rajendran et al., 1985). The delivery of cholesterol to luteal cells by LDL and HDL occurs by two distinct mechanisms, and it appears that, unlike LDL, the HDL molecule is not internalized (Paavola et al., 1985; Gwynne et al., 1985). PGF- $2 \alpha$ could inhibit utilization of LDL and HDL in a similar manner if the inhibition was imposed subsequent to cholesterol entry into the cell.

The rate-limiting step of steroid synthesis is the cleavage of the cholesterol side chain, brought about by the action of the mitochondrial cytochrome P-450 enzyme complex. It is possible that PGF- $2 \alpha$ inhibits this important step in the conversion of cholesterol to progestagen, thereby 
preventing the utilization of lipoprotein-derived cholesterol. Alternatively, PGF- $2 \alpha$ could prohibit the transport of cholesterol to the mitochondria, thereby rendering it unavailable for side-chain cleavage. Microtubules are involved in the transport and use of LDL in cultured rat luteal cells (Rajan \& Menon, 1985) and the cytoskeleton is involved in the transport of cholesterol to the mitochondria (Hall, 1985). One potential action of PGF-2 $\alpha$ could be to disrupt the cytoskeletal network, thus preventing movement of accumulated cholesterol to the mitochondria. However, at this time further investigation is required to determine whether PGF-2 $\alpha$ can directly affect cytoskeletal elements.

The results of this study also represent the first report that PGF- $2 \alpha$ can directly decrease de-novo cholesterol synthesis. Although the mechanism of this action is unknown, this could occur in response to cytoskeletal disruption, which results in a decline in the activity of HMG-CoA reductase (Volpe, 1979). By whatever mechanism, the direct suppression of cholesterol synthesis by PGF-2 $\alpha$, as well as allowance for lipoprotein-induced suppression of this process, represents another way in which PGF-2 $\alpha$ decreases cholesterol availability.

PGF- $2 \alpha$ was not as effective an inhibitor of sterol synthesis as either LDL or HDL, but it was equally effective in decreasing the incorporation of $\left[{ }^{14} \mathrm{C}\right]$ acetate into progesterone. Again, this indicates that PGF-2 $\alpha$ probably has multiple sites of action, i.e. to suppress synthesis of cholesterol, but also to prevent formation of steroid from any cholesterol that is produced. In contrast, the lipoproteins probably acted only on the cholesterol synthetic process, resulting in a subsequent decrease in ${ }^{14} \mathrm{C}$-labelled progesterone, without influencing the rate of conversion of sterol to steroid.

In conclusion, it has been demonstrated by these experiments that cholesterol synthesis as well as progesterone production in bovine luteal cells is regulated by the availability of lipoprotein. In addition, PGF- $2 \alpha$ can inhibit lipoprotein-enhanced steroidogenesis, and probably acts at a site subsequent to entry of cholesterol into the luteal cell. PGF-2 $\alpha$ itself can also suppress de-novo sterol synthesis, further limiting the pool of cholesterol which would be available for progesterone synthesis.

We thank Janet P. Poff and Leslie S. Jones for excellent technical assistance; Michelle Vernier for help in the preparation of the manuscript; Dr G. D. Niswender for the progesterone antiserum; and Dr Salvatore Raiti of the-National Hormone and Pituitary Program of the NIADDK, NIH, for the LH used in this study. Salaries and rèsearch support provided by State and Federal funds appropriated to the Ohio Agricultural Research and Development Center, manuscript No. 195-88, and the Ohio Dairy Farmers Federation.

\section{References}

Armstrong, D.T. \& Black, D.L. (1966) Influence of luteinizing hormone on corpus luteum metabolism and progesterone biosynthesis throughout the bovine estrous cycle. Endocrinology 78, 937-944.

Balasubramaniam, S., Goldstein, J.L., Faust, J.R., Brunschede, G.Y. \& Brown, M.S. (1977) Lipoproteinmediated regulation of 3-hydroxy-3-methylglutaryl coenzyme: A reductase activity and cholesterol ester metabolism in the adrenal gland of the rat. J. biol. Chem. 252, 1771-1779.

Baranao, J.L.S. \& Hammond, J.M. (1985) FSH stimulates de novo synthesis of cholesterol in cultured porcine granulosa cells. In Lipoprotein and Cholesterol Metabolism in Steroidogenic Tissues, pp. 39-42. Eds J. F. Strauss III \& K. M. J. Menon. George F. Stickley Co., Philadelphia.

Brown, M.S. \& Goldstein, J.L. (1980) Multivalent feed- back regulation of HMG CoA reductase, a control mechanism coordinating isoprenoid synthesis and cell growth. J. Lipid Res. 21, 505-517.

Carr, B.R., MacDonald, P.C. \& Simpson, E.R. (1980) The regulation of de novo synthesis of cholesterol in the human fetal adrenal gland by low density lipoprotein and adrenocorticotropin. Endocrinology 107, $1000-1006$.

Condon, W.A. \& Black, D.L. (1976) Catecholamineinduced stimulation of progesterone by the bovine corpus luteum in vitro. Biol. Reprod. 15, 573-578.

Gwynne, J.T. \& Strauss, J.F., III (1982) The role of lipoproteins in steroidogenesis and cholesterol metabolism in steroidogenic glands. Endocrine Rev. 3, 299-329.

Gwynne, J.T., Hess, B., Hughes, T., Holland, S., Rountree, R., Mahaffee, D., Irsula, O. \& Reynolds, J. 
(1985) The "HDL pathway" in the rat adrenal cortex. In Lipoprotein and Cholesterol Metabolism in Steroidogenic Tissues, pp. 111-124. Eds J. F. Strauss III \& K. M. J. Menon. George F. Stickley Co., Philadelphia.

Hall, P.F. (1985) The role of the cytoskeleton in the supply of cholesterol for steroidogenesis. In Lipoprotein and Cholesterol Metabolism in Steroidogenic Tissues, pp. 207-218. Eds J. F. Strauss III \& K. M. J. Menon. George F. Stickley Co., Philadelphia.

Havel, R.J., Eder, H.A. \& Bragdon, J.H. (1955) The distribution and chemical composition of ultracentrifugally separated lipoprotein in human serum. J. clin. Invest. 34, 1345-1353.

Heath, E., Weinstein, P., Merritt, B., Shanks, R. \& Hixon, J. (1983) Effects of prostaglandins on the bovine corpus luteum: granules, lipid inclusions and progesterone secretion. Biol. Reprod. 29, 977-985.

O'Shaughnessy, P.J. \& Wathes, D.C. (1985) Role of lipoproteins and de novo cholesterol synthesis in progesterone production by cultured bovine luteal cells. J. Reprod. Fert. 74, 425-432.

Pate, J.L. \& Condon, W.A. (1982) Effects of serum and lipoproteins on steroidogenesis in cultured bovine luteal cells. Molec. cell. Endocr. 28, 551-562.

Pate, J.L. \& Nephew, K.P. (1988) Effects of in vivo and in vitro administration of prostaglandin $F-2 \alpha$ on lipoprotein utilization in cultured bovine luteal cells. Biol. Reprod. 38, 568-576.

Paavola, L.G., Strauss, J.F., III, Boyd, C.O. \& Nestler, J.E. (1985) Cellular uptake of high and low density lipoproteins by rat ovarian cells. In Lipoprotein and Cholesterol Metabolism in Steroidogenic Tissues, pp. 171-186. Eds J. F. Strauss \& K. M. J. Menon. George F. Stickley Co., Philadelphia.

Rajan, V.P. \& Menon, K.M.J. (1985) Role of microtubules in lipoprotein transport in cultured rat luteal cells. In Lipoprotein and Cholesterol Metabolism in Steroidogenic Tissues, pp. 197-200. Eds J. F. Strauss III \& K. M. J. Menon. George F. Stickley Co., Philadelphia.

Rajendran, K.G., Menon, M., Peegel, H., Hwang, J. \& Menon, K.M.J. (1985) The role of plasma lipoproteins in steroidogenic response of rat luteal cells during gonadotropin-induced refractory states. Can. J. Physiol. Pharmacol. 63, 265-272.

Rajkumar, K., Couture, R.L. \& Murphy, B.D. (1985) High density lipoprotein uptake and utilization by rat corpora lutea. The effects of prolactin and prostaglandin F-2 $\alpha$. In Lipoprotein and Cholesterol Metabolism in Steroidogenic Tissues, pp. 147-154. Eds J. F. Strauss III \& K. M. J. Menon. George F. Stickley Co., Philadelphia.

Rosenblum, M.F., Huttler, C.R. \& Strauss, J.F., III (1981) Control of sterol metabolism in cultured rat granulosa cells. Endocrinology 109, 1518-1527.
Savion, N., Laherty, R., Cohen, D., Lui, G.-M. \& Gospodarowicz, D. (1982) Role of lipoproteins and 3hydroxy-3-methylglutaryl coenzyme/A reductase in progesterone production by cultured bovine granulosa cells. Endocrinology 110, 13-22.

Schreiber, J.R., Hsueh, A.J.W., Weinstein, D.B. \& Erickson, G.F. (1980) Plasma lipoproteins stimulate progestin production by rat ovarian granulosa cells cultured in serum free medium. J. Steroid Biochem. 13, 1009-1014.

Schuler, L.A., Scavo, L., Kirsch, T.M., Flickinger, G.L. \& Strauss, J.F., III (1979) Regulation of de novo biosynthesis of cholesterol and progestins, and formation of cholesteryl ester in rat corpus luteum by exogenous sterol. J. biol. Chem. 254, 8662-8668.

Schuler, L.A., Toaff, M.A. \& Strauss, J.F., III (1981) Regulation of ovarian cholesterol metabolism: control of 3-hydroxy-3-methylglutaryl coenzyme A reductase and acyl coenzyme A: cholesterol acyltransferase. Endocrinology 1108, 1476-1486.

Simpson, E.R., Porter, J.C., Milewich, L., Bilheimer, D.W. \& MacDonald, P.C. (1978) Regulation by plasma lipoproteins of progesterone biosynthesis and 3-hydroxy-3-methyl glutaryl coenzyme A reductase activity in cultured human choriocarcinoma cells. $J$. clin. Endocr. Metab. 47, 1099-1105.

Skipski, V.P. \& Barclay, M. (1969) Thin-layer chromatography of lipids. In Methods in Enzymology, pp. $530-598$. Ed. M. J. Lowenstein. Academic Press, New York.

Swann, R.T. \& Bruce, N.W. (1986) Acetate and plasma cholesterol as progesterone precursors in the intact ovary of the day-16 pregnant rat. J. Reprod. Fert. 77, 655-664.

Talavera, F., Park, C.S. \& Williams, G.L. (1985) Relationships among dietary lipid intake, serum cholesterol and ovarian function in holstein heifers. J. Anim. Sci. 60, 1045-1051.

Tureck, R.W. \& Strauss, J.F., III (1982) Progesterone synthesis by luteinized human granulosa cells in culture: the role of de novo sterol synthesis and lipoprotein-carried sterol. J. clin. Endocr. Metab. 54, 367-373.

Umo, I. (1975) Effect of prostaglandin F-2 $\alpha$ on the ultrastructure and function of sheep corpora lutea. $J$. Reprod. Fert. 43, 287-292.

Volpe, J.J. (1979) Microtubules and the regulation of 3-hydroxy-3-methylglutaryl coenzyme $A$ reductase. J. biol. Chem. 254, 2568-2571.

Wybenga, D.R., Pileggi, V.J., Dristine, P.H. \& DiGiorgio, J. (1970) Direct manual determination of serum total cholesterol with a single stable reagent. Clin. Chem. 16, 980-984.

Received 22 December 1988 